\title{
Sand Goanna (Varanus gouldii) Predation on a Painted Dragon (Ctenophorus pictus) and a Mulga Parrot (Psephotellus varius) in South Australia
}

\author{
Gerrut Norval $^{1 *}$, Robert D. Sharrad ${ }^{1}$, and Michael G. Gardner ${ }^{1,2}$ \\ ${ }^{1}$ College of Science and Engineering, Flinders University, Adelaide, South Australia, Australia, \\ (gerrut.norval@flinders.edu.au, robert.sharrad@flinders.edu.au, michael.gardner@flinders.edu.au) \\ ${ }^{2}$ Evolutionary Biology Unit, South Australian Museum, North Terrace Adelaide 5000, South Australia, Australia
}

Photographs by the senior author.

$\mathrm{P}$ redation can substantially influence biotic communities and is therefore an important aspect of the natural history of both predator and prey (Sih et al. 1985). Predation is rarely observed and often is inferred through the examination of digestive tract contents of predators. This unfortunately entails the collection and sacrifice of animals from the wild, which can be perceived as unethical if not part of a larger project. However, the collection and dissection of predators found dead on roads is an ethical practice for obtaining information on prey utilized by the predator.

The Sand Goanna, Varanus gouldii (Gray 1838) (Fig. 1), is a large varanid indigenous to most of the more arid regions of continental Australia and the dry savannahs of southern New Guinea (Cogger 2014). Herein we report on the stomach contents of a Sand Goanna found dead on a dirt road (Fig. 2) in the Mid North region of South Australia.

At $1910 \mathrm{~h}$ on 15 October 2017, the senior author found a male Sand Goanna dead (Fig. 3) on Salford Road

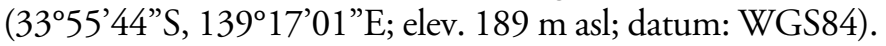

The surrounding habitat is an ecotone between chenopod shrubland and mallee scrubland and was dominated by Red Mallee Trees (Eucalyptus oleosa), and the shrubs Bladder Saltbrush (Atriplex vesicaria), Bluebush (Maireana sedifolia), and Spiny Goosefoot (Rhagodia ulicina). The lizard was collected, measured, and dissected to examine its digestive tract contents. It had a snout-vent length, tail length, and body mass of $345 \mathrm{~mm}, 493 \mathrm{~mm}$, and $769 \mathrm{~g}$, respectively. The stomach contained the partly digested remains of an adult Painted Dragon, Ctenophorus pictus (Peters 1866), and a chick of the Mulga Parrot, Psephotellus varius Clark 1910. No scavenging insects (e.g., ants and beetles) were present, which indicated that the prey items were not carrion that had been scavenged by the lizard. To the best of our knowledge, neither $C$. pictus nor $P$. varius have been recorded as prey of $V$. gouldii.

Sand Goannas are opportunistic predators that prey on a large variety of invertebrates and vertebrates, as well as carrion (Pianka 1970; Shine 1986; Losos and Greene 1988; Thompson 1995). The considerable variation in the diet of

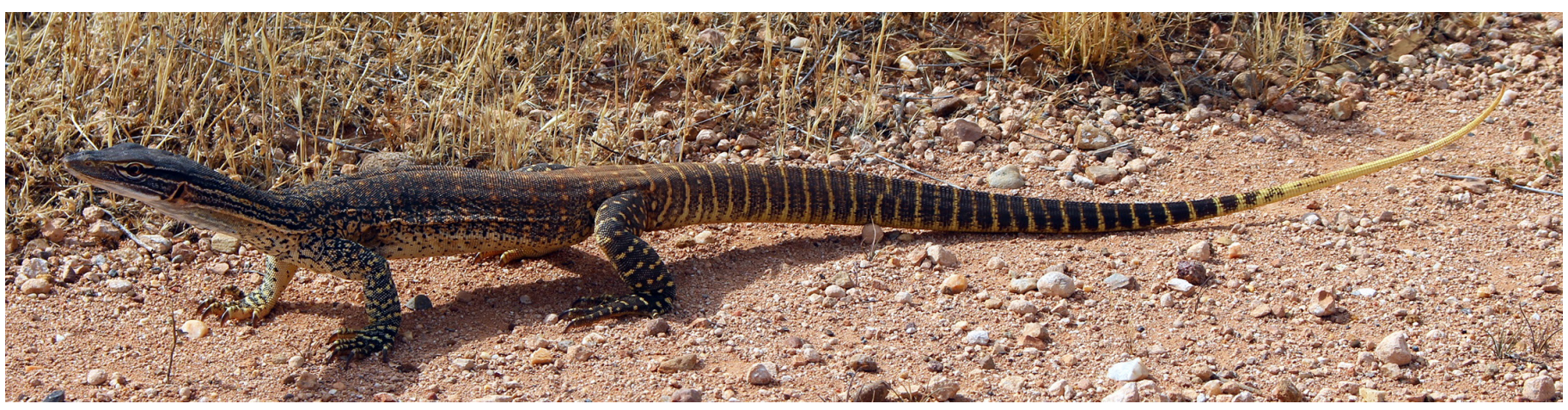

Fig. 1. The Sand Goanna (Varanus gouldii) is a large, relatively common lizard of the more arid regions of Australia. Note the large claws and powerful forelimbs that these lizards use for excavating prey from their burrows. 


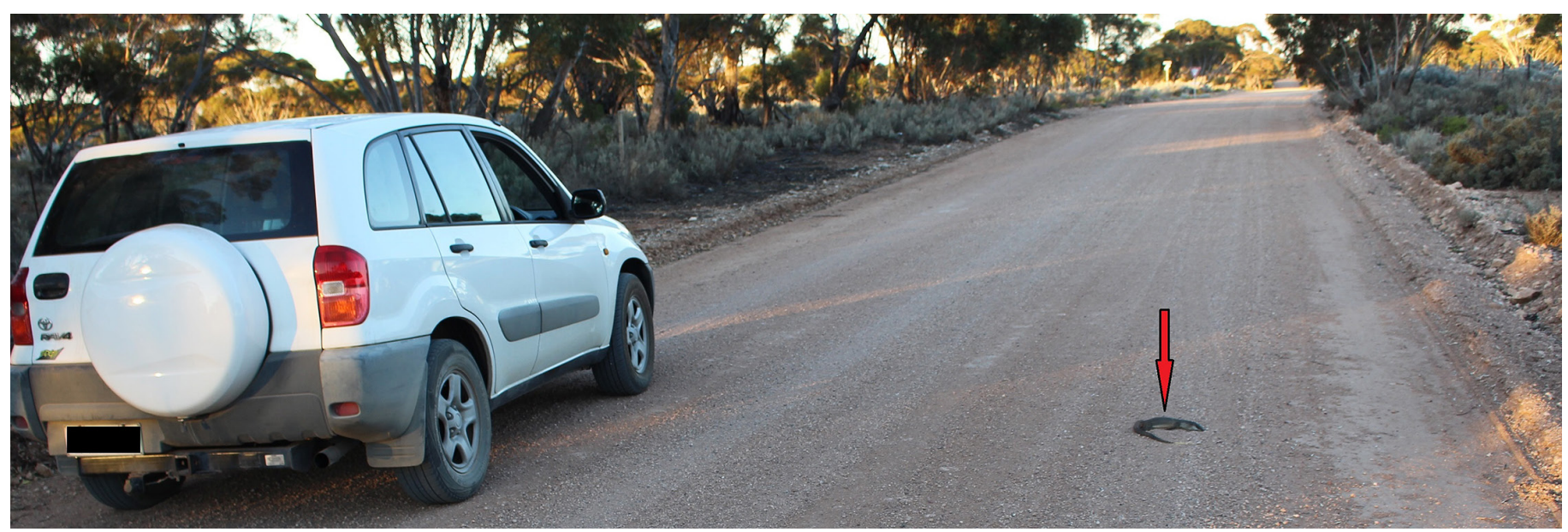

Fig. 2. The position of the road-killed Sand Goanna (Varanus gouldii) described herein. Note the chenopod scrubland and mallee shrubland ecotone on both sides of the road.

this species is likely a reflection of prey availability. These lizards are active foragers and may travel great distances in search of prey, detecting them visually or by using olfactory cues (Pianka 1970; Thompson 1995). Painted Dragons are fast moving lizards that make use of shallow burrows (Cogger 2014), and the Sand Goanna most likely captured the Painted Dragon by excavating it from its burrow. Whether the Sand Goanna preyed upon the Mulga Parrot chick while it was still in its nest or whether it was found on the ground cannot be determined. Sand Goannas are primarily terrestrial (Pianka 1970), although they will prey on eggs and nestlings of nests built near the ground (White 1952). Pianka (1970) recorded parts of two chicks of an unidentified bird as well as several species of arboreal lizards from the stomachs of Sand Goannas. King (1978) also reported unidenti-

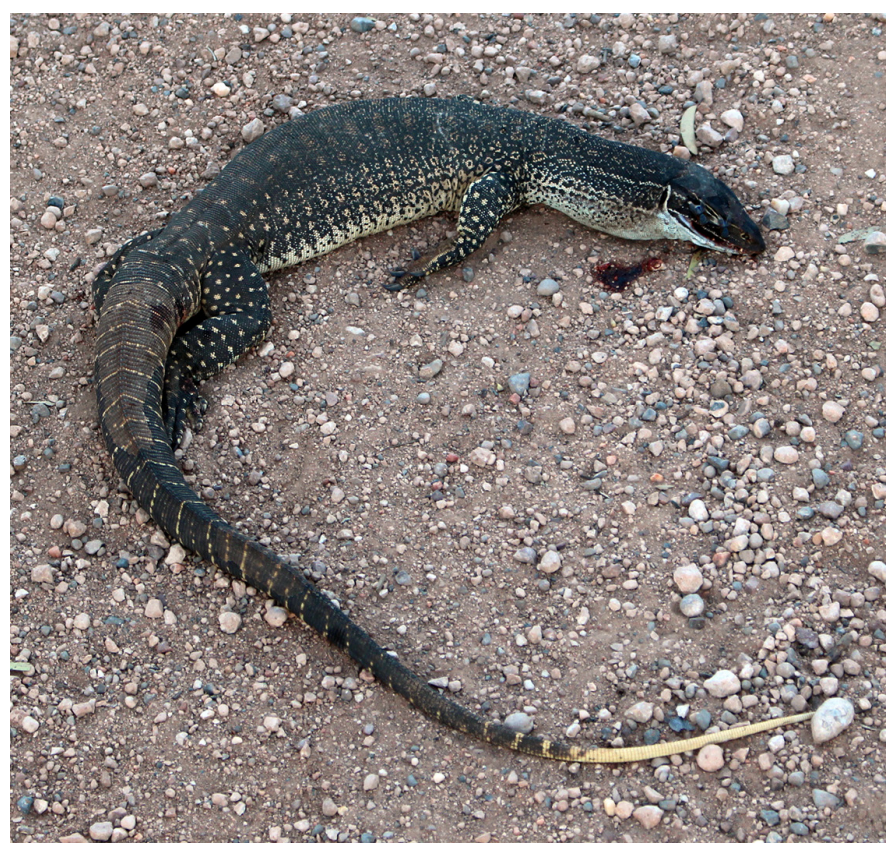

Fig. 3. The road-killed Sand Goanna (Varanus gouldii) described herein as it was found on the dirt road. fied bird remains from Sand Goanna scats that were collected in South Australia, and Shine (1986) recorded an Emerald Dove, Chalcophaps indica (Linnaeus 1758), and another unidentified bird in the stomachs of these lizards. In addition, Thompson (1995) reported on a Sand Goanna that climbed into a shrub to forage. These observations suggest that under some conditions Sand Goannas may take prey in trees. This and other aspects of the natural history of Sand Goannas in South Australia warrant further empirical studies.

\section{Acknowledgements}

This observation was made by the senior author while conducting field work as part of his doctoral research, which was partly funded in 2017 by a grant from the Royal Society of South Australia. Clearance for the research was granted by the Animal Welfare Committee of Flinders University (No.: E454/17) and the Department of Environment, Water and Natural Resources of the Government of South Australia (Permit No.: A23436-25).

\section{Literature Cited}

Cogger, H.G. 2014. Reptiles and Amphibians of Australia. 7th ed. CSIRO Publishing, Collingwood, Victoria, Australia.

King, R.D. 1978. Temperature regulation in the Sand Goanna, Varanus gouldii (Gray). Unpublished Ph.D. Thesis, University of Adelaide, Adelaide, South Australia, Australia.

Losos, J.B. and H.W. Greene. 1988. Ecological and evolutionary implications of diet in monitor lizards. Biological Journal of the Linnean Society 35: 379-407.

Pianka, E.R. 1970. Notes on the biology of Varanus gouldii flavirufus. The Western Australian Naturalist 11: 141-144.

Shine, R. 1986. Food habits, habitats and reproductive biology of four sympatric species of varanid lizards in tropical Australia. Herpetologica 42: 346-360.

Sih, A., P. Crowley, M. McPeek, J. Petranka, and K. Strohmeier. 1985. Predation, competition, and prey communities: A review of field experiments. Annual Review of Ecology and Systematics 16: 269-311.

Thompson, G.G. 1995. Foraging patterns and behaviours, body postures and movement speed for goannas, Varanus gouldii (Reptilia: Varanidae), in a semi-urban environment. Journal of the Royal Society of Western Australia 78: $107-114$

White, S.R. 1952. Destruction of nestling birds by reptiles. Western Australian Naturalist 3: 119-120. 